Available at http://jurnal.stie-aas.ac.id/index.php/jap

Jurnal Akuntansi dan Pajak, 19(02), 2019, 116-133

\title{
Pengaruh Sistem Pengendalian Internal Terhadap Pencapaian Good Government Governance Melalui Pencegahan Dan Pengungkapan Fraud
}

\author{
Yasmi Nurdin*, Fahriah Tahar, Nurbayani \\ Fakultas Ekonomi dan Ilmu Sosial, Universitas Fajar \\ *Email korenpondensi: yasmi@unifa.ac.id
}

\begin{abstract}
This study examines the extent of perception of government's internal auditors (BPKP) in assessing the ability of the government's internal control system (SPIP) to detect and prevent fraud and encouraging the achievement of Good Government Governance $(G G G)$ in the government agencies. Using the survey method to BPKP auditors at the South Sulawesi representative office and the PLS approach as a statistical tool, empirical facts were found, SPIP had a significant effect on the fraud prevention, fraud disclosure, and achievement of GGG. Moreover, Fraud Control Plan (FCP) also has a significant influence on the achievement of GGG. These results indicate the importance of periodically evaluating the effectiveness of SPIP and FCP by BPKP, in order to doing further improvement of these systems for reaching the $G G G$.
\end{abstract}

Keywords: BPKP, Good Government Governance, Government, Internal auditor, SPIP

Saran sitasi: Nurdin, Y., Tahar, F., \& Nurbayani, N. (2019). Pengaruh Sistem Pengendalian Internal Terhadap Pencapaian Good Government Governance Melalui Pencegahan dan Pengungkapan Fraud. Jurnal Akuntansi dan Pajak, 19(2), 116-133. doi:http://dx.doi.org/10.29040/jap.v19i2.312

DOI: http://dx.doi.org/10.29040/jap.v19i2.312

\section{Pendahuluan}

Setelah memasuki era reformasi dan desentralisasi serta untuk mencapai Good Government Governance, pemerintah Indonesia mempunyai kewajiban memberantas berbagai jenis korupsi, seperti korupsi pengadaan barang dan jasa, penyuapan, pencucian uang, dan penyalahgunaan anggaran yang begitu banyak. Mulai dari tingkat pusat hingga ke daerah-daerah di penjuru nusantara (KPK, 2017b, 2017a). Hal tersebut selaras dengan fakta yang juga ditunjukkan oleh Corruption Perception Index-Transparency International yang masih menempatkan Indonesia di peringkat 90 dari 176 negara didunia sebagai salah satu negara dengan tingkat korupsi yang cukup tinggi (Transparency International, 2016). Akibatnya, kewajiban pemberantasan korupsi tidak boleh main-main dan haruslah didukung oleh ketersediaan hukum, pengetahuan, sistem dan pendekatan yang efektif, karena kewajiban tersebut terus mendapat tantangan dengan modus korupsi dari para koruptor yang semakin canggih (SUARA.COM, 2015). Lebih lanjut, juga karena Good Government Governance (GGG) hanya dapat dicapai sebagai salah satu tujuan reformasi jika korupsi dapat diberantas (Eriyanto, 2010).

Dalam proses pemberantasan korupsi, dibutuhkan pemahaman komprehensif guna dapat memahami motif yang mendasari tindakan para pelakunya, sehingga tindakan pencegahan dan pengungkapan dapat dilakukan dengan tepat sasaran. ACFE (Association of Certified Fraud Examiners) menjelaskan motif yang melatar belakangi kasus korupsi dapat dijelaskan secara ringkas dengan istilah "Fraud Triangle" yang mempunyai tiga elemen utama penyebab fraud termasuk korupsi yaitu Opportunity, Motives, dan Rationalization (ACFE, 2006). Dengan pemahaman yang baik atas elemen tersebut maka 
seharusnya organisasi dapat mengurangi potensi fraud (Cendrowski \& Martin, 2007; Manning, 2005) dan mengungkap kasusnya (Bierstaker, Brody, \& Pacini, 2006; Tuanakotta, 2010) dengan cara mendesain suatu sistem pengendalian yang tepat (Rezaee \& Riley, 2010). Namun, pendapat berbeda diutarakan oleh Baker (1990) yang memandang meskipun suatu entitas memiliki sistem pengendalian intern yang baik, karyawan tetap dapat melakukan fraud dengan mengakali sistem pengendalian internal entitas tersebut. terutama jika motivasi dan kesempatan dimiliki oleh karyawan. Juga jika tekanan (pressure) dan rasionalisasi untuk membenarkan tindakan tersebut dialami oleh karyawan (Albrecht, Howe, \& Romey, 1984; Zahra, Priem, \& Rasheed, 2005).

Sistem pengendalian intern yang baik adalah sistem yang mampu menekan kemungkinan terjadinya fraud dan mengoptimalkan pendeteksian fraud (ACFE, 2006). Atas dasar tersebut, menciptakan dan menerapkan sistem pengendalian internal yang baik menjadi hal yang penting agar dapat mengendalikan fraud di suatu entitas (Rae \& Subramaniam, 2008). Lebih lanjut, Arens (2006) menyatakan, pentingnya melakukan pengendalian juga untuk memenuhi reliability of financial reporting, compliance with applicable laws and regulations, and effectiveness and efficiency of operation yang akan berujung pada minimalnya kesalahan dan fraud yang terjadi disuatu entitas. Hal tersebut juga selaras dengan pendapat Tuanakotta (2010) dan Graycar dan Sidebottom (2012) yang menyatakan upaya utama adalah melakukan pencegahan agar fraud tidak terjadi, sebab fraud yang tidak terdeteksi cenderung lebih banyak dibandingkan fraud yang terdeteksi.

Sejalan dengan amanat reformasi di bidang pemerintahan yang menuntut pengelolaan $\mathrm{Ne}$ gara yang akuntabel, transparan dan bersih dari korupsi (fraud), Presiden Republik Indonesia menetapkan Peraturan Pemerintah Nomor 60 Tahun 2008 tentang "Sistem Pengendalian Internal Pemerintah" (SPIP). Sistem ini diharapkan dapat memberi keyakinan bagi tercapainya efektifitas dan efisiensi pencapaian tujuan penyelenggaraan Negara, keandalan pelaporan keuangan, pengamanan aset Negara, dan ketaatan terhadap peraturan perundang-undangan Sehingga seluruh instansi pemerintah seharusnya menerapkan sistem pengendalian tersebut agar tercapai pengelolaan Negara yang akuntabel dan transparan.

SPIP pada dasarnya merupakan adopsi dari versi Commite of Sponsoring Organization (COSO) (BPKP, 2010) dan selaras dengan amanat Persatuan Bangsa-Bangsa (UN) agar pemerintah-pemerintah dunia mencapai Good Government Governance (GGG) (BPKP, 2010). Sebagaimana yang tergambar dalam dokumen what is good governance?

"Good governance has 8 major characteristics. It is participatory, consensus oriented, accountable, transparent, responsive, effective and efficient, equitable and inclusive and follows the rule of law. It assures that corruption is minimized...(UNDP, 2011)"

Dengan kata lain, SPIP merupakan alat untuk menunjang tercapainya Good Governance di instansi pemerintah.

Hadirnya PP Nomor 60 Tahun 2008 atau SPIP ini menuntut BPKP, sebagai auditor internal pemerintah, untuk berperan aktif dalam penerapan sistem pengendalian internal di instansi-instansi pemerintah. Khususnya dalam bidang Pengawasan Internal yang berkaitan dengan seluruh proses kegiatan audit, reviu, evaluasi, pemantauan, dan kegiatan pengawasan lain terhadap penyelenggaraan aktifitas instansi pemerintah agar terwujud tata pemerintahan yang sesuai dengan aturan berlaku. Hal ini selaras dengan hasil penelitian Sarens dan De Beelde (2006) yang menemukan hubungan antara hasil kinerja auditor internal yang digunakan sebagai bahan evaluasi sistem pengendalian internal entitas. Juga penelitian Bierstaker et al. (2006) yang menyatakan bahwa auditor internal berperan dalam mencegah dan mendeteksi fraud.

Terdapat beberapa penelitian sebelumnya terkait peran internal auditor dan pengendalian 
internal terhadap pencegahan fraud (Badara \& Saidin, 2013; Bierstaker et al., 2006; Law, 2011; Rae \& Subramaniam, 2008; Sarens \& De Beelde, 2006; Vinten, Alleyne, \& Howard, 2005). Penelitian tersebut menemukan bukti bahwa pengendalian internal terbukti efektif dalam mencegah dan mendeteksi fraud di lingkup entitas yang profit-oriented. Namun penelitian terkait hubungan antara penerapan sistem pengendalian internal dan pengaruhnya terhadap pencapaan Good Government Governance belum banyak dilakukan. Terutama dari perspektif pengendalian internal pemerintah dan pengaruhnya atas pencapaian Good Government Governance versi United Nations (PBB) yang menilai accountability, transparency, efficiency, dan effectivity dari suatu instansi pemerintah (UNDP, 2011).

Penelitian terdahulu baru melihat pencapaian sistem pengendalian internal atas Good Government Governance, per-element seperti akuntabilitas (Cavalluzzo \& Ittner, 2004), transparansi (Bertot, Jaeger, \& Grimes, 2010; Carlo Bertot et al., 2012), dan efisiensi dan efektifitas (Croom \& Brandon-Jones, 2007). Sedangkan untuk hubungan antara pencegahan dan pengungkapan fraud atas pencapaian good government governance belum banyak yang spesifik membahasnya. Berdasarkan hal tersebut, perlu dilakukan penelitian dari sisi penerapan sistem pengendalian internal, khususnya pengendalian internal pemerintah dalam upaya pencegahan, pengungkapan fraud serta pengaruhnya atas pencapaian Good Government Governance.

Ide penelitian ini berdasar penelitian yang dilakukan bahwa internal control system memiliki pengaruh untuk mengamankan aset entitas dan meningkatkan akuntabilitas entitas (Bierstaker et al., 2006; Graycar \& Sidebottom, 2012; Kuhn Jr, Ahuja, \& Mueller, 2013; Law, 2011; Vinten et al., 2005). Namun perlu dilakukan penelitian lebih lanjut terkait manfaat praktek internal audit sebagai komponen pengendalian internal dari perspektif internal auditor dan jenisjenis kebijakan internal control system lainnya
(Rae \& Subramaniam, 2008; Sarens \& De Beelde, 2006).

Penelitian ini kemudian mencoba menilai penerapan SPIP serta hubungannya dengan pencapain Good Government Governance melalui pencegahan dan pengungungkapan fraud di instansi-instansi pemerintah yang diawasi oleh BPKP. Berdasar pada PP Nomor 60 Tahun 2008 yang mewajibkan BPKP sebagai auditor Presiden untuk melakukan pengawasan dan penyelenggaraan SPIP. Penelitian ini memilih auditor BPKP Provinsi Sulawesi Selatan sebagai objek penelitian dengan alasan BPKP Sulawesi Selatan termasuk BPKP yang memiliki daerah kerja yang begitu luas sebab bertanggungjawab mengawasi dua provinsi yakni sulawesi selatan dan barat dengan total 31 kabupatan/kota (24 Sulawesi Selatan dan 7 Sulawesi Barat). Selain itu, BPKP Sulawesi Selatan dianggap dapat menjadi representasi gambaran kondisi pemerintahan di Indonesia timur yang masih jarang dikaji dalam diskursus pengendalian internal pemerintah di Indonesia.

Permasalahan proposal penelitian ini adalah bagaimana penilaian auditor di BPKP atas penerapan SPIP di instansi pemerintah selama ini sehingga mampu mencapai Good Government Governance melalui pencegahan dan pendeteksian fraud. Penelitian ini kemudian berusaha mengkonfirmasi antara goodness of fit dan empirical data. Lebih jauh, hasil penelitian ini diharapkan dapat memberikan manfaat sebagai berikut: (1) bagi pengembangan disiplin ilmu akuntansi, sehingga dapat memperkuat teori-teori mengenai pemahaman terhadap sebuah sistem baru, serta menambah referensi di bidang kajian organisasi publik. (2) Bagi praktisi dan intitusi, khususnya auditor internal dari perwakilan BPKP di tiap Provinsi sebagai bahan masukan dalam penentuan kebijakan dan evaluasi SPIP.

\section{Tinjauan Pustaka}

\subsection{Persepsi}

Kottler dan Keller (2008) mengemukakan persepsi sebagai proses bagaimana seseorang menyeleksi, mengatur, dan menginterpretasikan masukan-masukan informasi untuk menciptakan 
gambaran keseluruhan yang berarti sehingga dapat mempengaruhi prilaku dan membentuk sikap yang berbeda atau sama antara individu dan individu yang lain. Penelitian ini akan membahas persepsi auditor BPKP mengenai pengaruh penerapan SPIP terhadap pencapaian Good Government Governance pada instansiinstansi pemerintah yang diawasi oleh BPKP melalui pencegahan dan pengungkapan fraud. Tanggapan dari para auditor BPKP diperlukan secara langsung karena, BPKP memiliki kewajiban untuk memberikan keyakinan yang memadai atas ketaatan, kehematan, efisiensi, dan efektivitas pencapaian tujuan penyelenggaraan tugas dan fungsi Instansi Pemerintah, memberikan peringatan dini dan meningkatkan efektivitas manajemen risiko dalam penyelenggaraan tugas dan fungsi Instansi Pemerintah, dan memelihara serta meningkatkan kualitas tata kelola penyelenggaraan tugas dan fungsi Instansi Pemerintah (BPKP, 2010, 2017).

\subsection{Fraud}

Penelitian ini menggunakan istilah fraud bukan korupsi, karena istilah korupsi merupakan salah satu cabang dari tindakan fraud itu sendiri. Hal ini merujuk pada pernyataan ACFE (2006) yaitu "The three major types of occupational fraud are: Corruption, Asset Misappropariation, and Fraudulent Statement". Hal itu senada dengan pernyataan Jones dan Bates (1990), Manning (2005), Pedneault, Silverstone, Rudewicz, \& Sheetz (2012), dan Vona (2012) yang menyatakan klasifikasi fraud adalah penggelapan yang terdiri dari berbagai kecurangan, seperti penipuan yang disengaja (intentional deceit), pemalsuan rekening (falsification of account), praktik jahat (corrupt practices), penggelapan atau pencurian (embezzlement), dan korupsi (corruption). Kondisi tersebut terjadi dikarenakan adanya keinginan yang disengaja dan mengesampingkan pengetahuan atau dapat dikatakan akibat bertemunya tiga faktor (fraud triangle) yaitu opportunity, pressure, dan rasionalization dari pelakunya (Tuanakotta, 2010).

Dalam penelitian ini, sistem pengendalian intern dihubungkan dengan kemampuannya untuk membantu pencegahan fraud serta mengungkap fraud untuk mencapai Good Government Governance di instansi-instansi pemerintah. Pencegahan fraud yang dimaksud merupakan bagian dari aktivitas yang dilaksanakan melalui penetapan kebijakan, sistem dan prosedur di suatu entitas (Vona, 2012).

\subsection{Pengendalian Internal}

Boynton dan Johnson (2006) menyatakan bahwa pengendalian internal adalah tindakan perlindungan atas aset entitas dari tindakan akuisisi, penggunaan, dan disposisi yang tidak sah. Selanjutnya, Arens (2006) menjelaskan komponen utama pengendalian internal terdiri dari control environment, risk assessment, information and communication, control activities, monitoring. Kelima komponen pengendalian internal tersebut haruslah saling berhubungan (integrated) agar pengendalian dapat berjalan dengan efektif (William Jr, Glover, \& Prawitt, 2016). Selain itu, juga agar dapat membantu manajemen untuk memenuhi reliability of financial reporting (keandalan pelaporan keuangan), compliance with applicable laws and regulations (pemenuhan peraturan dan hukum), dan effectiveness and efficiency of operation (Arens, 2006).

\subsection{Audit Internal}

Sebagai bagian integral dari komponen pengendalian internal, tepatnya komponen control activities. Audit internal merupakan suatu fungsi dalam entitas yang berfokus untuk menguji dan mengevaluasi aktivitas-aktivitas entitas dengan cara menganalisa, menilai, memberikan rekomendasi, bimbingan, dan memberikan informasi sehubungan dengan aktivitas yang dievaluasi berdasar standar internal yang telah ditetapkan perusahaan. Dimana hasilnya akan digunakan top management sebagai sumber informasi yang dapat diandalkan mengenai entitas yang dipimpinnya.

Seiring berjalannya waktu, auditor internal diarahkan menuju peran yang lebih luas, khususnya terkait pengelolaan resiko, pengendalian, dan tata kelola atas suatu entitas (Cangemi \& Singleton, 1996; Moeller, 2009). 
Pickett (2010) kemudian menjabarkan ruang lingkup audit internal yang terdiri dari penilaian atas (1) akurat dan handalnya informasi finansial dan operasional, (2) resiko-resiko di entitas, (3) ketaatan atas aturan internal maupun eksternal (pemerintah),(4) pencapaian kualitas kerja operasional, (5) efisien dan ekonomisnya penggunaan sumberdaya entitas, (6) efektifitas pencapaian tujuan entitas. Selanjutnya, disebabkan tantangan fraud yang semakin kompleks di dunia bisnis serta di pemerintahan. Auditor internal kemudian juga diharuskan memahami lingkungan organisasi sehingga dapat membantu menentukan risiko terjadinya fraud (Moeller, 2009). Sehingga ruang lingkup internal auditor semakin luas yang mencakup pendeteksian (pengungkapan) dan pencegahan terjadinya fraud.

\subsection{Sistem Pengendalian Internal Pemerintah} (SPIP)

Dalam konteks pemerintahan, pemerintah Indonesia juga memiliki Sistem Pengendalian Internal Pemerintah (SPIP) berdasar pada PP Nomor 60 Tahun 2008 yang bertujuan untuk memberikan keyakinan memadai bagi tercapainya efektifitas dan efisiensi pencapaian tujuan penyelenggaraan pemerintahan Negara, keandalan pelaporan keuangan, pengamanan aset Negara, dan ketaatan terhadap peraturan perundang-undangan. Sepintas pengendalian internal menurut PP Nomor 60 Tahun 2008 terlihat memiliki kesamaan dengan konsep pengendalian internal di bidang privat. Hal ini ditemukan pada lima unsur SPIP yaitu: (1) Lingkungan pengendalian (2) Penilaian Resiko (3) Kegiatan Pengendalian (4) Informasi dan komunikasi (5) Pemantauan pengendalian internal. Dalam penerapannya, SPIP bertujuan untuk mencapai pengelolaan keuangan yang efektif, efisien, transparan dan akuntabel yang kemudian mewajibkan menteri/pimpinan lembaga Negara, gubernur, dan bupati/walikota untuk melakukan pengendalian atas penyelenggaraan kegiatan pemerintah di instansinya masing-masing.

Dengan kata lain, SPIP adalah sistem yang diselenggarakan secara menyeluruh di lingkungan pemerintah pusat hingga daerah dengan tujuan mencapai tata kelola pemerintahan yang baik (Good Government Governance). Lebih lanjut, dalam pengaplikasiaan SPIP, BPKP sebagai auditor internal pemerintah adalah instansi yang ditunjuk guna memastikan penerapan tersebut berjalan dengan baik (BPKP, 2010, 2017).

\subsection{Good Government Governance}

Tuntutan atas Good Government Governance di Indonesia mulai mengemuka seiring bergulirnya era reformasi. Dikenal sebagai salah satu amanat reformasi, yang salah satu isinya adalah menghadirkan birokrasi yang bersih dari korupsi (Eriyanto, 2010). United Nations Development Programme dan World Bank (UNDP, 2011) mendefenisikan Governance sebagai suatu proses pembuatan dan pengimplementasian kebijakan publik yang melibatkan interaksi sosial, politik, ekonomi antara pemerintah, sektor swasta, dan masyarakat dalam rangka mencapai tujuan bersama (all stakeholders' objective) dan pembangunan berkelanjutan di masyarakat. Dimana suatu instansi pemerintah dapat dikatakan telah mencapai Good Governance jika telah memiliki karekteristik (1) Participatory (2) Consensus oriented (3) Accountable (4)Transparant (5) Responsive (6) Effective and Efficient (7) Equitable (UNDP, 2011).

Jika diperhatikan seksama, terdapat kesamaan antara karekteristik pencapaian Good Governance versi UNDP dan tujuan dari Sistem Pengendalian Internal Pemerintah (PP Nomor 60 tahun 2008) dalam hal memberikan keyakinan memadai atas tercapainya tujuan organisasi melalui kegiatan yang efektif dan efisien, keandalan pelaporan keuangan, pengamanan aset negara, dan ketaatan terhadap peraturan perundang-undangan yang merupakan inti dari Good Government Governance.

\subsection{Kerangka Konseptual Penelitian}

Penelitian terkait Sistem Pengendalian Internal Pemerintah dalam konteks Indonesia masih jarang dilakukan, Hal ini disebabkan PP Nomor 60 Tahun 2008 masih terbilang baru diterapkan setelah melewati proses sosialisasi 
yang cukup panjang. Namun, di beberapa negara lain, penelitian terkait Sistem Pengendalian Internal sudah cukup banyak dilakukan khususnya, terkait dampaknya terhadap pencegahan dan penggungkapan fraud serta dampaknya terhadap pencapaian Good Governance.

Beberapa penelitian yang telah dilakukan terkait sistem pengendalian intern, audit internal, pencegahan, pengungkapan fraud, serta pencapaian Good Governance, sayangnya, masih cenderung berfokus pada sektor privat (Bierstaker et al., 2006; Croom \& Brandon-Jones, 2007; Graycar \& Sidebottom, 2012; Law, 2011; Rae \& Subramaniam, 2008; Sarens \& De Beelde, 2006; Vinten et al., 2005). Atas dasar tersebut, penelitian penerapan sistem pengendalian internal dapat dikatakan masih sangat relevan dilakukan dalam konteks pemerintahan dan Indonesia. Terlebih dalam konteks persepsi aktor yang terlibat langsung, yakni auditor internal pemerintah.

Berdasarkan teori yang telah diuraikan sebelumnya dan penelitian terdahulu, guna menganalisa persepsi auditor intern pemerintah atas penerapan Sistem Pengendalian Intern Pemerintah (SPIP) terhadap pencapaian Good Government Governance melalui pencegahan fraud dan pengungkapan fraud, maka kerangka konseptual untuk penelitian ini disusun sebagaiman Gambar 1.

\subsection{Pengembangan Hipotesis}

\section{Hubungan sistem pengendalian internal terhadap pencegahan fraud}

Persepsi individu dengan individu yang lain terhadap suatu objek sangat mungkin memiliki perbedaan (Robbins \& Judge, 2006). Berdasarkan hal tersebut, maka persepsi seorang internal auditor dapat berbeda terhadap suatu hal yang telah cukup lama diterapkan, namun belum diterapkan secara merata di instansi pemerintah, khususnya terkait manfaat penerapan SPIP itu sendiri. Persepsi auditor akan positif jika merasakan manfaat atas penerapan SPIP terhadap pencegahan dan pengungkapan fraud, juga atas pencapaian Good Government Governance. Sebaliknya jika persepsi auditor negatif, maka SPIP masih dirasa belum mampu mencapai tujuannya tersebut.

BPKP sebagai instansi yang diamanatkan oleh PP Nomor 60 Tahun 2008 wajib memastikan penerapan SPIP di instansi pemerintah berfungsi dengan baik agar fraud dapat dicegah. Hal tersebut selaras dengan konsep pengendalian

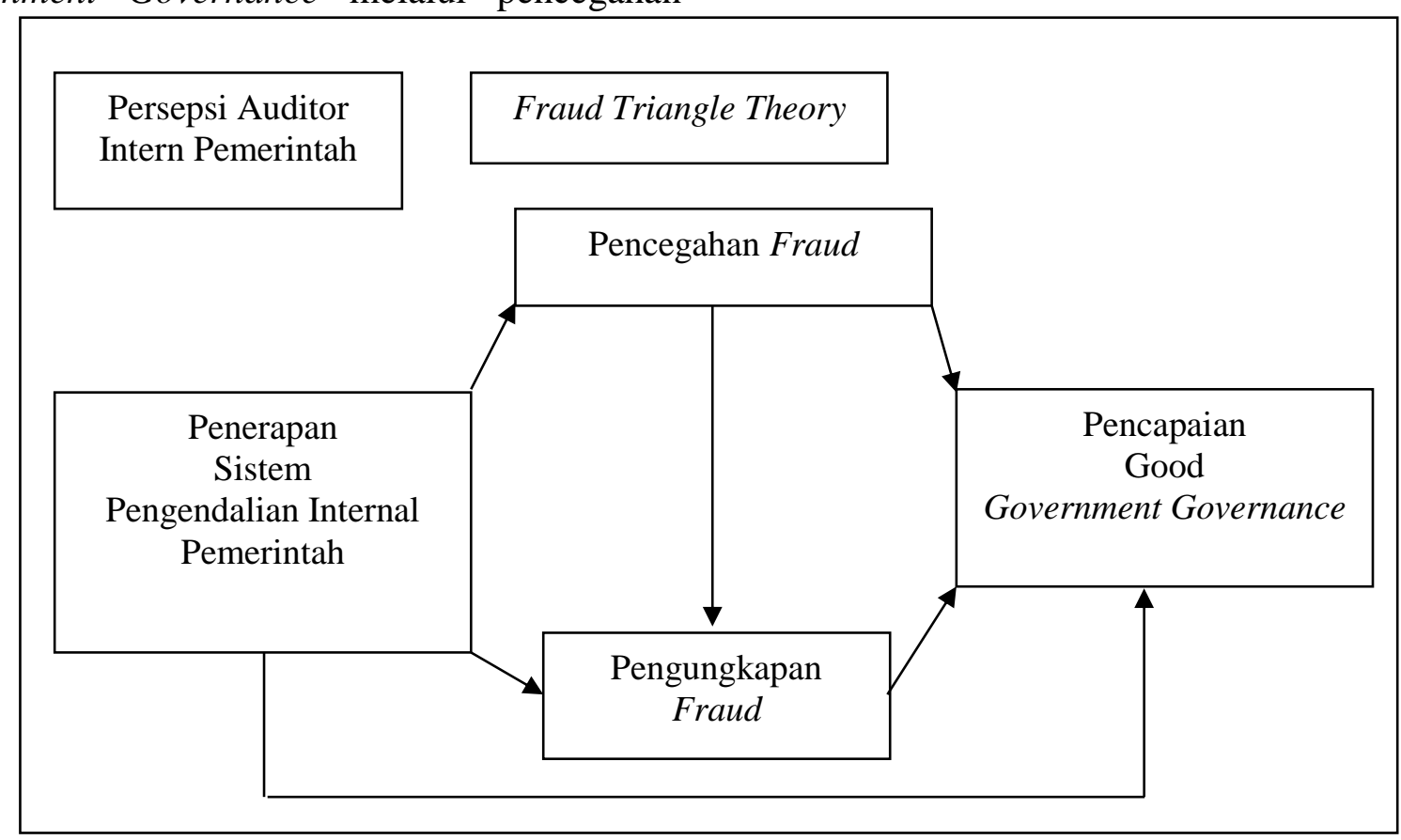

Gambar Kerangka Konseptual Penelitian

Sumber: Diolah untuk penelitian ini 
internal yang menyatakan bahwa aktivitas pengendalian internal meliputi kebijakan, sistem, dan prosedur yang membantu dewan komisaris, manajemen, dan karyawan untuk dapat memberikan keyakinan memadai terkait pencapaian organisasi seperti efektifitas dan efisiensi organisasi, keandalan pelaporan keuangan, dan kepatuhan terhadap hukum dan peraturan yang berlaku (Moeller, 2009; Pickett, 2010). Juga menurut hasil penelitian Rae dan Subramaniam (2008), Vinten et al. (2005), serta Law (2011) yang menyatakan sistem pengendalian internal mempengaruhi berkurangnya fraud yang terjadi di suatu entitas. Berdasarkan pendapat-pendapat tersebut, maka peneliti merumuskan hipotesa penelitian terkait pengaruh penerapan SPIP terhadap pencegahan fraud sebagai berikut:

H1: SPIP berpengaruh positif terhadap pencegahan fraud

\section{Hubungan sistem pengendalian internal terhadap pengungkapan fraud}

Beberapa penelitian terdahulu menunjukkan terdapat hubungan antara penerapan sistem pengendalian internal disuatu entitas dengan kemampuan auditor mengungkap fraud (Bierstaker et al., 2006; Vinten et al., 2005). Meskipun demikian, terdapat literatur yang menemukan hal yang sebaliknya, bahwa banyak kasus fraud yang terjadi dilakukan dengan cara mengakali sistem pengendalian internal yang menyebabkan pengungkapan serta pembuktian fraud oleh auditor serta pemeriksa menjadi lebih sulit (Graycar \& Sidebottom, 2012; Tuanakotta, 2010). Berdasar hal tersebut, selaras dengan tujuan SPIP untuk menjadikan kinerja instansi pemerintah taat hukum yang salah satu unsurnya adalah penindakan atas fraud yang terjadi. Maka peneliti merumuskan hipotesa penelitian terkait pengaruh penerapan SPIP terhadap pengungkapan fraud yang dilakukan oleh auditor internal sebagai berikut:

$\mathrm{H} 2$ : SPIP berpengaruh positif terhadap pengungkapan fraud

Hubungan sistem pengendalian internal terhadap tingkat transparansi, akuntabilitas, efektifitas, dan efisiensi kinerja instansi
Tujuan penerapan SPIP di Instansi pemerintah adalah untuk mencapai pengelolaan keuangan negara yang efektif, efisien, transparan, dan akuntabel (PP Nomor 60 Tahun 2008). Hal ini selaras dengan amanat PBB (United Nations) terkait pentingnya menghadirkan tata kelola pemerintahan yang baik (Good Government Governance) untuk mencapai pembangunan yang berkelanjutan dan setara (UNDP, 2011). Beberapa penelitian telah mengungkapkan bahwa penerapan sistem pengendalian intern dengan berbagai jenis pengembangannya seperti penerapan Information Technology (Kuhn $\mathrm{Jr}$ et al., 2013), Management system serta e-procurement (Croom \& Brandon-Jones, 2007) dapat membantu entitas mencapai efisiensi, efektifitas serta akuntabilitas. BPKP sebagai instansi auditor internal pemerintah menjadi instansi yang bertanggung jawab langsung kepada Presiden untuk memastikan pencapaian hal-hal tersebut. maka persepsi auditor BPKP sebagai auditor internal pemerintah menjadi penting terkait penilaian atas pencapaian efektifitas, efisiensi, akuntabilitas, dan transparansi entitas pemerintah yang telah menerapkan SPIP.

Berdasar hal tersebut, maka peneliti merumuskan hipotesa penelitian terkait pengaruh penerapan SPIP terhadap pencapaian transparansi, akuntabilitas, efektifitas, dan efisiensi kinerja instansi yang dinilai oleh auditor internal sebagai berikut:

H3: SPIP berpengaruh positif terhadap pencapaian transparansi, akuntabilitas, efektifitas, dan efisiensi kinerja instansi

Hubungan pencegahan fraud terhadap tingkat transparansi, akuntabilitas, efektifitas, dan efisiensi kinerja instansi

Tuanakotta (2010) berpendapat bahwa pencegahan fraud mampu meningkatkan kinerja suatu entitas menjadi lebih efisien serta efektif. Pendapat yang sama juga diutarakan oleh Vinten et al. (2005) serta Bierstaker et al. (2006) yang menyatakan bahwa tindakan pencegahan fraud membuat kinerja entitas lebih efektif, efisien, serta menjadi taat hukum (peraturan) yang berlaku. Selaras dengan hal tersebut, BPKP juga 
telah mengembangkan konsep Fraud Control Plan sebagai bagian dari SPIP yang ditujukan untuk mencegah terjadinya fraud di instansi pemerintah (BPKP, 2010). Maka peneliti merumuskan hipotesa penelitian terkait pengaruh tindakan pencegahan fraud terhadap pencapaian transparansi, akuntabilitas, efektifitas, dan efisiensi kinerja instansi yang dinilai oleh auditor internal sebagai berikut:

H4: Tindakan pencegahan fraud berpengaruh positif terhadap pencapaian transparansi, akuntabilitas, efektifitas, dan efisiensi kinerja instansi

\section{Hubungan pencegahan fraud terhadap pengungkapan fraud}

Menurut Bierstaker et al.(2006), Graycar dan Sidebottom (2012), dan Law (2011) bahwa entitas yang melakukan tindakan pencegahan fraud cenderung membantu auditor internal maupun eksternal untuk mengungkap fraud yang terjadi di entitas tersebut. Namun penelitian tersebut mengambil objek di entitas privat. Atas dasar hal tersebut peneliti tertarik melakukan pengujian di entitas pemerintah dengan merumuskan hipotesis sebagai berikut:

H5: Tindakan pencegahan fraud berpengaruh positif terhadap pengungkapan fraud

Hubungan pengungkapan fraud terhadap tingkat transparansi, akuntabilitas, efektifitas, dan efisiensi kinerja instansi

Tuanakotta (2010) berpendapat terdapat hubungan antara pengungkapan fraud yang berlanjut dengan proses hukum terhadap peningkatan kinerja entitas. Khususnya di Negara seperti Indonesia yang masih memiliki budaya hirarki yang begitu kuat. Sehingga jika pimpinan suatu instansi diproses hukum akibat terungkap melakukan fraud maka bawahannya cenderung akan merubah kinerjanya sehingga menjauhi tindakan fraud. Atas dasar itu peneliti mengembangkan hipotesis sebagai berikut:

H6: Tindakan pengungkapan fraud berhubungan positif terhadap tingkat transparansi, akuntabilitas, efektifitas, dan efisiensi kinerja instansi.

\section{Metode Penelitian}

\subsection{Desain dan Sampel Penelitian}

Penelitian ini menggunakan metode kuantitatif dengan menguji hipotesis yang akan menjelaskan fenomena bentuk hubungan antar variabel. Jenis data yang digunakan dalam penelitian ini adalah data subyek penelitian (responden) yang berupa persepsi dan diukur menggunakan skala likert, sebab dianggap tepat untuk mengukur tingkat emosi, kebutuhan personal, personalitas dan penggambaran suatu pekerjaan (Aprilia \& Ghozali, 2013). Sumber data penelitian ini adalah data primer yang berasal dari jawaban responden atas pertanyaanpertanyaan yang diajukan peneliti. Pengambilan data diserahkan secara langsung kepada responden dengan instrumen yang digunakan berupa kuesioner berbasis kertas dan google survey sejak akhir februari hingga april 2018. Unit analisis atau sampel penelitian ini adalah auditor pada kantor perwakilan BPKP provinsi Sulawesi Selatan.

\subsection{Variabel Penelitian dan Defenisi Operasional}

Variabel-variabel yang digunakan dalam penelitian ini adalah Sistem Pengendalian Internal Pemerintah (SPIP), tindakan pencegahan fraud, tindakan pengungkapan fraud, dan pencapaian Good Government Governance (GGG) yang diukur dengan tingkat akuntabiltas, efisensi dan efektifitas, dan transparansi instansi pemerintah. Pertanyaan yang digunakan peneliti berfokus pada bagaimana penilaian auditor BPKP dalam melaksanakan tugas dan fungsi utamanya atas indikator-indikator penelitian ini yang diukur dalam enam (6) skala likert yakni (1) Sangat Buruk / Sangat Tidak Efektif, (2) Buruk / Tidak Efektif, (3) Sedikit Buruk / Kurang Efektif, (4) Cukup Baik / Cukup Efektif, (5) Baik / Efektif, (6) Sangat Baik / Sangat Efektif. Instrumen penelitian ini diadaptasi dan dikembangkan dari penelitian-penelitian terdahulu. Digambarkan sebagaimana Tabel 1 .

\subsection{Metode Uji Hipotesis}

Metode uji hipotesis yang digunakan pada penelitian ini adalah menggunakan SEM-PLS (Structural Equation Model-Partially Least Square) dengan menggunakan software.

SmartPLS (Ghozali \& Latan, 2015). Untuk mengetahui apakah ada pengaruh antara 
penerapan SPIP terhadap pencapaian Good Government Governance melalui pencegahan dan pengungkapan fraud

\section{Hasil dan Pembahasan \\ 4.1 Hasil penelitian \\ Analisis Deskriptif Data Responden}

Di dalam penelitian ini dikumpulkan data primer melalui penyebaran kuesioner kepada responden yang menjadi sampel penelitian. Pada analisis deskriptif ini, data responden dijelaskan melalui tabel tunggal. Adapun gambaran deskriptif data responden dalam penelitian ini adalah sebagaimana Tabel 2.

\section{Analisis Model penelitian}

Analisis model penelitian ini menggunakan alat Struktural Equation Modeling (SEM) Partial Least Square (PLS). Dikarenakan alat analisis ini tepat untuk menguji secara simultan antara multiple eksogen dan endogen variabel dengan banyak indikator serta merupakan metode analisis yang powerfull karena tidak didasarkan banyak asumsi. Data tidak harus berdistribusi normal secara multivariate, baik indikator reflektif maupun formatif dengan skala nominal,

Tabel 1. Defenisi Operasional Variabel

\begin{tabular}{|c|c|c|}
\hline Konstruk Laten & Dimensi & Indikator Konstruk \\
\hline \multicolumn{3}{|l|}{ Eksogen } \\
\hline Sistem Pengendalian & \multirow{5}{*}{$\begin{array}{l}\text { Persepsi responden } \\
\text { terhadap pemahaman } \\
\text { dan penerapan sistem } \\
\text { pengendalian internal }\end{array}$} & Lingkungan Pengendalian \\
\hline Internal Pemerintah & & Penilaian Resiko \\
\hline (SPIP) & & Aktivitas Pengendalian \\
\hline & & Informasi dan Komunikasi \\
\hline \multicolumn{2}{|l|}{ Endogen } & \\
\hline $\begin{array}{l}\text { Pencegahan Fraud } \\
\text { (Y1) }\end{array}$ & \multirow{5}{*}{$\begin{array}{l}\text { Persepsi responden } \\
\text { terhadap kebijakan } \\
\text { pencegahan fraud } \\
\text { yang dilakukan oleh } \\
\text { instansi pemerintah }\end{array}$} & $\begin{array}{l}\text { Kebijakan anti fraud } \\
\text { Struktur pertanggungjawaban } \\
\text { Penilaian resiko fraud }\end{array}$ \\
\hline \multirow[t]{4}{*}{$\begin{array}{l}\text { - Fraud Control Plan } \\
\text { (BPKP, 2010) }\end{array}$} & & $\begin{array}{l}\text { Kepedulian Pegawai } \\
\text { Kepedulian masyarakat }\end{array}$ \\
\hline & & $\begin{array}{l}\text { Sistem pelaporan kejadian fraud } \\
\text { Perlindungan pelapor }\end{array}$ \\
\hline & & $\begin{array}{l}\text { Pengungkapan kepada pihak eksternal } \\
\text { Prosedur investigasi }\end{array}$ \\
\hline & & Standar perilaku dan disiplin \\
\hline Pengungkapan Fraud & \multirow{9}{*}{$\begin{array}{l}\text { Persepsi responden } \\
\text { terhadap tindakan } \\
\text { pengungkapan fraud } \\
\text { yang dilakukan oleh } \\
\text { auditor internal } \\
\text { pemerintah }\end{array}$} & Mereview internal control \\
\hline$(\mathrm{Y} 2)$ & & Melakukan cross-check kepada pegawai \\
\hline & & Melakukan fraud auditing \\
\hline \multirow[t]{6}{*}{-Bierstaker et al. (2006) } & & Memanfaatkan whistle-blowing program \\
\hline & & Melakukan audit operasional \\
\hline & & $\begin{array}{l}\text { Menggunakan jasa akuntan Iorensik } \\
\text { Melakukan review atas kas }\end{array}$ \\
\hline & & $\begin{array}{l}\text { Melakukan observasi atas } \\
\text { persediaan/aset }\end{array}$ \\
\hline & & Melakukan rekonsiliasi Bank \\
\hline & & Menggunakan fraud software \\
\hline Pencapaian Good & Persepsi responden & tingkat transparansi instansi pemerintah \\
\hline Government Governance & terhadap pencapaian & tingkat akuntabilitas instansi pemerintah \\
\hline $\begin{array}{l}\text { (Y3) } \\
- \text { INDP }(0011)\end{array}$ & Good Government & tingkat efektifitas kinerja instansi \\
\hline & instansi pemerintah & $\begin{array}{l}\text { tingkat efisiensi kinerja instansi } \\
\text { pemerintah }\end{array}$ \\
\hline
\end{tabular}


Tabel 2. Deskripsi Responden

\begin{tabular}{lccccccccccc}
\hline Auditor & Jum. & $\%$ & Usia & Jum & $\%$ & Pend. & Jum & $\%$ & P/W & Jum & $\%$ \\
\hline Ahli & 3 & 9 & $20-29$ & 21 & 62 & D3 & 1 & 3 & P & 24 & 71 \\
Madya & 3 & 9 & $30-39$ & 5 & 14 & S2/S3 & 3 & 9 & W & 10 & 29 \\
Muda & 5 & 15 & $40-49$ & 4 & 12 & S1 & 30 & 88 & Total & 34 & 100 \\
Penyelia & 1 & 3 & $50-59$ & 4 & 12 & Total & 34 & 100 & & & \\
Pertama & 21 & 62 & Total & 34 & 100 & & & & & & \\
Penata & 1 & 3 & & & & & & & & & \\
Total & 34 & 100 & & & & & & & & & \\
\hline
\end{tabular}

ordinal, interval bahkan rasio bisa digunakan dalam model yang sama, selain itu sampel minimal yang di perlukan tidak harus besar (Ghozali \& Latan, 2015).

\section{Model Pengukuran (Outer model / Measure- ment Model)}

Measurement model merupakan model dengan hasil perhitungan berdasarkan perhitungan menggunakan program PLS. Tujuan dari model pengukuran (measurement model) adalah untuk menggambarkan indikator mana yang memiliki pengaruh dominan sebagai pengukur langsung variabel latent. Evaluasi terhadap validitas dari model pengukuran dapat dilakukan dengan melihat hasil estimasi loading atau weight faktornya (Ghozali \& Latan, 2015). Karena penelitian ini termasuk statistik deskriptif bukan statistik inferensial dan termasuk confirmatory research maka nilai signifikansi pada evaluasi tidak kritis, dan tidak terpengaruh dengan kriteria kelayakan sebagaimana pengujian dalam sampel, karena data yang digunakan adalah data sensus atau populasi. Dan peneliti bertujuan ingin mengkonfirmasi teori yang sudah baku dan berlaku umum pada populasi yang ada. Sehingga tidak perlu dilakukan re-estimasi. sehingga evaluasi hanya mengkonfirmasi nilai pengaruh loading factor atau weight estimate mana yang berkontribusi paling dominan (Ghozali \& Latan, 2015). Adapun ringkasan penilaian statistik atas model penelitian ini adalah sebagaimana Tabel 3.

Berdasarkan Tabel 3, dapat diketahui bahwa seluruh nilai Loading factor dalam variabel lebih besar dari 0,5 yang berarti indikator dinyatakan layak (valid), meskipun terdapat 1 item yang dinyatakan tidak valid namun item tersebut masih dapat dipertahankan karena secara OverAll sudah bagus, hal ini dibuktikan dengan nilai AVE > 0.5 (Valid), dan nilai Composite Reliability seluruhnya mimiliki nilai lebih besar dari 0,700 (Reliabel). Dengan demikian secara umum hasil optimasasi lokal (outer model) dinyatakan baik dan layak untuk dilanjutkan analisis selanjutnya. Secara detail, guna mengetahui indikator yang paling dominan dalam memberikan kontribusi terhadap konstruk laten dijelaskan pada Tabel 3.

Indikator yang paling baik dalam membentuk variabel Sistem Pengendalian Internal Pemerintah (X) adalah X1 (Lingkungan Pengendalian) dengan loading faktor tertinggi sebesar 0,879 , sehingga apabila pihak pengambil keputusan ingin meningkatkan nilai Sistem Pengendalian Internal Pemerintah (X) maka rekomendasi secara statistik adalah memprioritaskan peningkatan nilai pada indikator X1, yaitu unsur Lingkungan Pengendalian di instansi pemerintah.

Selanjutnya, indikator yang paling baik dalam membentuk variabel Pencegahan Fraud (Y1) adalah Y1.03 (Penilaian resiko fraud) dengan loading faktor tertinggi sebesar 0,861 , sehingga apabila pihak pengambil keputusan ingin meningkatkan nilai Pencegahan Fraud (Y1) maka rekomendasi secara statistik adalah memprioritaskan peningkatan nilai pada indikator Y1.03 (Penilaian resiko fraud).

Begitu juga dengan indikator yang paling baik dalam membentuk variabel Pengungkapan Fraud (Y2) adalah Y2.05 (Melakukan audit operasional) dengan loading faktor tertinggi 
Jurnal Akuntansi dan Pajak, 19(02), 2019, 126

Tabel 3. Ringkasan Evaluasi Model Pengukuran / Outer Model

\begin{tabular}{|c|c|c|c|c|c|c|c|c|}
\hline \multirow{3}{*}{ Variabel Laten } & \multirow{3}{*}{$\begin{array}{l}\text { Variabel } \\
\text { Teramati }\end{array}$} & \multicolumn{5}{|c|}{ Validitas Konvergen } & \multirow{2}{*}{\multicolumn{2}{|c|}{$\begin{array}{l}\text { Composite } \\
\text { Reliability } \\
(\mathrm{CR}>0,7)\end{array}$}} \\
\hline & & \multicolumn{2}{|c|}{$(\mathrm{LF}>0,5=$ Valid $)$} & \multirow{2}{*}{ 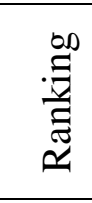 } & \multicolumn{2}{|c|}{$\begin{array}{c}\text { (AVE > } \\
0,5=\text { Valid) }\end{array}$} & & \\
\hline & & $\begin{array}{l}\text { Loading } \\
\text { Factor }\end{array}$ & $\begin{array}{c}\text { Kesim- } \\
\text { pulan }\end{array}$ & & AVE & $\begin{array}{l}\text { Kesim } \\
\text {-pulan }\end{array}$ & CR & Ket. \\
\hline \multirow{5}{*}{$\begin{array}{l}\text { Sistem Pengendalian } \\
\text { Internal Pemerin-tah (X) }\end{array}$} & $\mathrm{X} 1$ & 0,879 & Valid & 1 & \multirow{5}{*}{0,647} & \multirow{5}{*}{ Valid } & \multirow{5}{*}{0,901} & \multirow{5}{*}{ Reliabel } \\
\hline & $\mathrm{X} 2$ & 0,847 & Valid & 2 & & & & \\
\hline & $\mathrm{X} 3$ & 0,690 & Valid & 5 & & & & \\
\hline & $\mathrm{X} 4$ & 0,818 & Valid & 3 & & & & \\
\hline & $\mathrm{X} 5$ & 0,775 & Valid & 4 & & & & \\
\hline \multirow{10}{*}{ Pencega-han Fraud (Y1) } & Y1.01 & 0,813 & Valid & 4 & \multirow{10}{*}{0,565} & \multirow{10}{*}{ Valid } & \multirow{10}{*}{0,927} & \multirow{10}{*}{ Reliabel } \\
\hline & Y1.02 & 0,568 & Valid & 10 & & & & \\
\hline & Y1.03 & 0,861 & Valid & 1 & & & & \\
\hline & Y1.04 & 0,738 & Valid & 6 & & & & \\
\hline & Y1.05 & 0,814 & Valid & 3 & & & & \\
\hline & Y1.06 & 0,810 & Valid & 5 & & & & \\
\hline & Y1.07 & 0,716 & Valid & 7 & & & & \\
\hline & Y1.08 & 0,827 & Valid & 2 & & & & \\
\hline & Y1.09 & 0,607 & Valid & 9 & & & & \\
\hline & Y1.10 & 0,703 & Valid & 8 & & & & \\
\hline \multirow{10}{*}{$\begin{array}{l}\text { Pengung-kapan Fraud } \\
\text { (Y2) }\end{array}$} & Y2.01 & 0,905 & Valid & 5 & \multirow{10}{*}{0,719} & \multirow{10}{*}{ Valid } & \multirow{10}{*}{0,961} & \multirow{10}{*}{ Reliabe } \\
\hline & Y2.02 & 0,816 & Valid & 9 & & & & \\
\hline & Y2.03 & 0,948 & Valid & 2 & & & & \\
\hline & Y2.04 & 0,820 & Valid & 8 & & & & \\
\hline & Y2.05 & 0,950 & Valid & 1 & & & & \\
\hline & Y2.06 & 0,312 & $\begin{array}{l}\text { Tidak } \\
\text { Valid }\end{array}$ & 10 & & & & \\
\hline & Y2.07 & 0,909 & Valid & 4 & & & & \\
\hline & Y2.08 & 0,927 & Valid & 3 & & & & \\
\hline & Y2.09 & 0,878 & Valid & 6 & & & & \\
\hline & Y2.10 & 0,824 & Valid & 7 & & & & \\
\hline \multirow{4}{*}{$\begin{array}{l}\text { Pencapai-an Good } \\
\text { Govern-ment Gover- } \\
\text { nance (Y3) }\end{array}$} & Y3.1 & 0,851 & Valid & 4 & \multirow{4}{*}{0,781} & \multirow{4}{*}{ Valid } & \multirow{4}{*}{0,935} & \multirow{4}{*}{ Reliabel } \\
\hline & Y3.2 & 0,880 & Valid & 3 & & & & \\
\hline & Y3.3 & 0,883 & Valid & 2 & & & & \\
\hline & Y3.4 & 0,920 & Valid & 1 & & & & \\
\hline
\end{tabular}

sebesar 0,95, sehingga apabila pihak pengambil keputusan ingin meningkatkan nilai Pengungkapan Fraud (Y2) maka rekomendasi secara statistik adalah memprioritaskan peningkatan nilai pada indikator Y2.05 (Melakukan audit operasional).

Terakhir, indikator yang paling baik dalam membentuk variabel Pencapaian Good Government Governance (GGG) (Y3) adalah Y3.4
(Tingkat efisiensi kinerja Instansi pemerintah) dengan loading faktor tertinggi sebesar 0,92, sehingga apabila pihak pengambil keputusan ingin meningkatkan nilai Pencapaian Good Government Governance (Y3) maka rekomendasi secara statistik adalah memprioritaskan peningkatan nilai pada indikator Y3.4 (Tingkat efisiensi kinerja Instansi pemerintah). 
Jurnal Akuntansi dan Pajak, 19(02), 2019, 127

Tabel 4. Cross Loading (Discriminant validity)

\begin{tabular}{ccccc}
\hline & SPIP $(\mathrm{X})$ & $\begin{array}{c}\text { Pencegahan } \\
\text { Fraud }(\text { Y1 })\end{array}$ & $\begin{array}{c}\text { Pengungkapan } \\
\text { Fraud }(\text { Y2 })\end{array}$ & $\begin{array}{c}\text { Pencapaian } \\
\text { GGG (Y3) }\end{array}$ \\
\hline X1 & 0,879 & 0,691 & 0,516 & 0,698 \\
X2 & 0,847 & 0,730 & 0,406 & 0,580 \\
X3 & 0,690 & 0,581 & 0,191 & 0,640 \\
X4 & 0,818 & 0,678 & 0,545 & 0,545 \\
X5 & 0,775 & 0,702 & 0,497 & 0,531 \\
Y1.01 & 0,666 & 0,813 & 0,318 & 0,626 \\
Y1.02 & 0,539 & 0,568 & 0,343 & 0,355 \\
Y1.03 & 0,663 & 0,861 & 0,161 & 0,815 \\
Y1.04 & 0,592 & 0,738 & 0,214 & 0,582 \\
Y1.05 & 0,624 & 0,814 & 0,236 & 0,510 \\
Y1.06 & 0,582 & 0,810 & 0,203 & 0,580 \\
Y1.07 & 0,598 & 0,716 & 0,237 & 0,508 \\
Y1.08 & 0,702 & 0,827 & 0,217 & 0,741 \\
Y1.09 & 0,613 & 0,607 & 0,383 & 0,409 \\
Y1.10 & 0,708 & 0,703 & 0,313 & 0,717 \\
Y2.01 & 0,527 & 0,279 & 0,905 & 0,167 \\
Y2.02 & 0,438 & 0,311 & 0,816 & 0,164 \\
Y2.03 & 0,499 & 0,308 & 0,948 & 0,146 \\
Y2.04 & 0,511 & 0,420 & 0,820 & 0,291 \\
Y2.05 & 0,525 & 0,291 & 0,950 & 0,109 \\
Y2.06 & $-0,002$ & $-0,150$ & 0,312 & $-0,310$ \\
Y2.07 & 0,438 & 0,254 & 0,909 & 0,143 \\
Y2.08 & 0,456 & 0,260 & 0,927 & 0,133 \\
Y2.09 & 0,488 & 0,308 & 0,878 & 0,192 \\
Y2.10 & 0,457 & 0,327 & 0,824 & 0,116 \\
Y3.1 & 0,643 & 0,680 & 0,200 & 0,851 \\
Y3.2 & 0,607 & 0,712 & 0,133 & 0,880 \\
Y3.3 & 0,732 & 0,728 & 0,217 & 0,883 \\
Y3.4 & 0,641 & 0,698 & 0,097 & 0,920 \\
\hline & & & \\
\hline
\end{tabular}

Lebih lanjut, sebagaimana yang ditampakkan dalam tabel di atas, tampak bahwa nilai loading faktor atau cross loading secara umum $\geq$ 0,70 . Hal ini menunjukkan bahwa indikator yang digunakan dalam peneltian ini mampu menjelaskan variabel-variabel penelitian ini.

\section{Evaluasi Model Struktural (Uji Fit Model)}

Setelah model yang diestimasi memenuhi kriteria convergent validity dan discriminant validity, berikutnya dilakukan pengujian model struktural (inner model). Menilai inner model adalah melihat hubungan antara konstruk laten dengan melihat hasil estimasi koefisien para- meter path dan tingkat signifikansinya (Ghozali \& Latan, 2015). Sebagaimana Gambar 2.

Pengujian goodness of fit model penelitian dilakukan dengan menggunakan koefisien determinasi total, di mana hasil pengujian tersebut dapat menjelaskan seberapa besar model path yang terbentuk mampu merepresentasikan data yang diamati. Nilai koefisien determinasi total berkisar antara 0,0 hingga $100,0 \%$, di mana semakin tinggi nilai koefisien determinasi total maka semakin tinggi pula model path tersebut mampu untuk merepresentasikan data yang diamati signifikansinya (Ghozali \& Latan, 2015). 


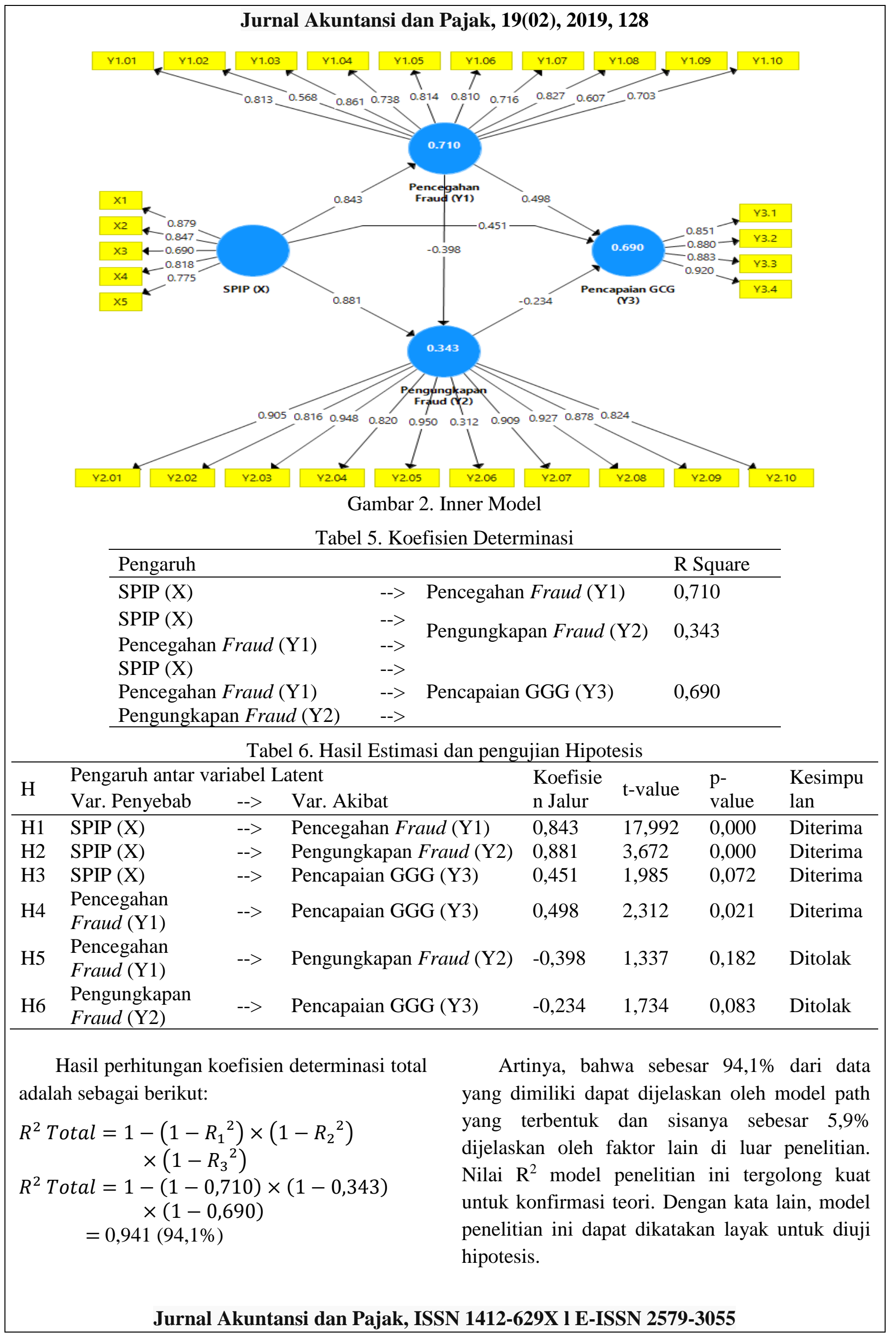




\section{Uji Hipotesis Penelitian}

Adapun ringkasan hasil analisis statistik dari program Smart PLS terkait dengan pengujian hipotesis penelitian ini adalah sebagaimana Tabel 6.

Berdasarkan data pada Tabel 6, dapat diketahui bahwa faktor yang paling dominan dalam mempengaruhi Pencapaian GGG (Y3) adalah Pencegahan Fraud (Y1) dengan koefisien jalur tertinggi sebesar 0,498. Ini artinya Pencegahan Fraud (Y1) lebih dominan berpengaruh terhadap Pencapaian GGG (Y3). Sedangkan Variabel Pencegahan Fraud (Y1) dan pengungkapan fraud (Y2) dipengaruhi oleh SPIP $(\mathrm{X})$, dimana diantara indikator yang paling dominan dalam mengukur konstruk SPIP (X) adalah X1 (Lingkungan Pengendalian) dengan loading faktor tertinggi sebesar 0,879 , sehingga apabila pihak pengambil keputusan, dalam hal ini BPKP dan instansi pemerintah, ingin meningkatkan nilai Sistem Pengendalian Internal Pemerintah (X) demi mencegah, mengungkapkan fraud dan mencapai GGG, maka rekomendasi secara statistik adalah memprioritaskan peningkatan nilai pada indikator X1. Dalam hal ini yaitu unsur Lingkungan Pengendalian.

\subsection{Pembahasan}

Hipotesis pertama (H1) yang menyatakan SPIP (Sistem Pengendalian Internal Pemerintah) berpengaruh positif terhadap pencegahan fraud dapat didukung. Hal tersebut didasarkan pada hasil uji statistik dalam penelitian ini yang menunjukkan nilai t-statistik SPIP signifikan berada di atas acuan nilai 1,96, nilai standar diterimanya hipotesis. Temuan penelitian ini sesuai dengan bangunan hipotesis yang dikembangkan dalam penelitian ini yang berdasar pada studi Rae dan Subramaniam (2008), Vinten et al. (2005), serta Law (2011) yang menyatakan sistem pengendalian internal mempengaruhi berkurangnya fraud yang terjadi di suatu entitas, dalam hal ini termasuk juga di entitas pemerintah. Lebih jauh, hasil ini juga bermakna, auditor internal pemerintah, yang menjadi responden penelitian ini, di BPKP Kantor Perwakilan Provinsi Sulawesi Selatan secara umum telah merasakan manfaat SPIP dalam mencegah terjadinya fraud di instansi pemerintah yang mereka awasi. Terakhir, temuan ini juga semakin mempertegas fungsi SPIP sebagai katalisator pencegahan fraud di instansi pemerintah sebagaimana yang diamanatkan oleh PP Nomor 60 Tahun 2008.

Selanjutnya, hipotesis kedua (H2) yang menyatakan SPIP berpengaruh positif terhadap pengungkapan fraud, juga terbukti berpengaruh signifikan secara statistik dalam penelitian ini. Hal tersebut didasarkan pada hasil uji statistik dalam penelitian ini yang menunjukkan nilai tstatistiknya signifikan berada di atas acuan nilai 1,96 , nilai standar diterimanya satu hipotesis. Hal ini selaras dengan studi terdahulu yang menunjukkan terdapat hubungan antara penerapan sistem pengendalian internal disuatu entitas dengan kemudahan auditor mengungkap fraud (Bierstaker et al., 2006; Vinten et al., 2005). Lebih penting lagi, temuan penelitian ini, khususnya dalam konteks persepsi auditor internal pemerintah, semakin mempertegas tercapainya salah satu tujuan SPIP untuk menjadikan kinerja instansi pemerintah taat hukum yang salah satu unsurnya adalah pengungkapan dan penindakan atas fraud yang terjadi. Terakhir, hasil ini juga bermakna, auditor internal pemerintah, yang menjadi responden penelitian ini, di BPKP Kantor Perwakilan Provinsi Sulawesi Selatan secara umum telah merasakan manfaat SPIP dalam mencegah terjadinya fraud di instansi pemerintah yang mereka awasi selama ini.

Berikutnya, hipotesis ketiga (H3) yang menyatakan SPIP berpengaruh positif terhadap pencapaian transparansi, akuntabilitas, efektifitas, dan efisiensi kinerja instansi (acuan pencapaian Good Government Governance) dapat didukung. Hal tersebut didasarkan pada hasil uji statistik dalam penelitian ini yang menunjukkan nilai tstatistiknya signifikan berada di atas acuan nilai 1,96, nilai standar diterimanya hipotesis. Temuan ini sesuai dengan bangunan hipotesis yang dikembangkan dalam penelitian ini yang 
berdasar pada studi terdahulu yang menyatakan penerapan sistem pengendalian intern dengan berbagai jenis pengembangannya seperti penerapan Information Technology (Kuhn $\mathrm{Jr}$ et al., 2013), Management system serta e-procurement (Croom \& Brandon-Jones, 2007) dapat membantu entitas mencapai efisiensi, efektifitas serta akuntabilitas. Lebih lanjut, hal ini semakin mempertegas fakta empiris bahwa dalam penugasan auditor BPKP Sulawesi Selatan, yang menjadi responden penelitian ini, mereka telah mendapatkan fakta atas pencapaian efektifitas, efisiensi, akuntabilitas, dan transparansi entitas pemerintah yang telah menerapkan SPIP di daerah kerja mereka. Di atas itu semua, hal ini juga menunjukkan keselarasan dengan amanat PP Nomor 60 Tahun 2008 tentang SPIP yang menunjukkan tujuan penerapan SPIP di Instansi pemerintah adalah untuk mencapai pengelolaan keuangan negara yang efektif, efisien, transparan, dan akuntabel dan amanat PBB (United Nations) terkait pentingnya menghadirkan tata kelola pemerintahan yang baik (Good Government Governance) untuk mencapai pembangunan yang berkelanjutan dan setara (UNDP, 2011).

Begitu juga dengan hipotesis keempat $(\mathrm{H} 4)$ yang menyatakan tindakan pencegahan fraud berpengaruh positif terhadap pencapaian transparansi, akuntabilitas, efektifitas, dan efisiensi kinerja instansi (acuan pencapaian Good Government Governance) dapat didukung. Hal tersebut didasarkan pada hasil uji statistik dalam penelitian ini yang menunjukkan nilai $t$ statistiknya signifikan berada di atas acuan nilai 1,96 , nilai standar diterimanya hipotesis. Hal ini selaras dengan pendapat para ahli dan studi terdahulu yang menjadi acuan pembangunan hipotesis ini. Sebagaimana yang diutarakan oleh Tuanakotta (2010), yang berpendapat bahwa pencegahan fraud mampu meningkatkan kinerja suatu entitas menjadi lebih efisien serta efektif. Vinten et al. (2005) sertaBierstaker et al. (2006) yang menyatakan bahwa tindakan pencegahan fraud membuat kinerja entitas lebih efektif, efisien, serta menjadi taat hukum (peraturan) yang berlaku. Lebih jauh, temuan ini juga menunjukkan dalam persepsi auditor BPKP Sulawesi Selatan, Fraud Control Plan-nya BPKP sebagai bagian dari SPIP yang ditujukan untuk mencegah terjadinya fraud di instansi pemerintah (BPKP, 2010), telah berjalan dengan baik dalam kerja-kerja audit mereka.

Berbeda dengan hipotesis sebelumnya, hipotesis kelima (H5) yang menyatakan tindakan pencegahan fraud berpengaruh positif terhadap terhadap pengungkapan fraud tidak dapat didukung. Dikarenakan hasil uji statistik dalam penelitian ini menunjukkan nilai t-statistiknya berada di bawah acuan nilai 1,96, nilai standar diterimanya hipotesis. Meskipun demikian, hal ini menunjukkan fenomena yang menarik, dapat diasumsikan persepsi auditor BPKP Sulawesi Selatan menemukan fakta di lapangan bahwa banyak kasus fraud yang terjadi dilakukan dengan cara mengakali sistem pengendalian internal yang menyebabkan pengungkapan serta pembuktian fraud oleh auditor serta pemeriksa menjadi lebih sulit. Hal ini senada dengan yang telah diungkapkan oleh (Graycar \& Sidebottom, 2012; Tuanakotta, 2010). Sebagaimana yang umum diketahui, kasus fraud,utamanya korupsi, di Indonesi semakin hari semakin canggih dalam mengakali sistem dan pemeriksa (SUARA.COM, 2015).

Begitu juga dengan hipotesis keenam (H6) yang menyatakan tindakan pengungkapan fraud berhubungan positif terhadap tingkat transparansi, akuntabilitas, efektifitas, dan efisiensi kinerja instansi (acuan pencapaian Good Government Governance) tidak dapat didukung. Dikarenakan hasil uji statistik dalam penelitian ini menunjukkan nilai t-statistiknya berada di bawah acuan nilai 1,96 , nilai standar diterimanya hipotesis. Temuan ini meski menolak bangunan hipotesis awal, dapat juga dibaca sebagai suatu peringatan dari persepsi auditor BPKP Sulawesi Selatan, bahwa terungkapnya suatu kasus fraud malah seharusnya dibaca sebagai tanda lemahnya atau belum tercapainya pencapaian Good Government Governance di instansi pemerintah. Hal ini semakin diperkuat dengan temuan statistik yang menunjukkan nilai koefisien jalurnya bernilai 
negatif $(-0,234)$ yang bermakna hasil pengukuran persepsi auditor BPKP menunjukkan terdapat hubungan negatif antara pengungkapan fraud dengan tercapainya transparansi, akuntabilitas, efektifitas, dan efisiensi kinerja di instansi pemerintah yang mereka awasi.

\section{Kesimpulan}

Berikut beberapa kesimpulan yang dapat diambil dari penelitian ini: (1) Sistem Pengendalian Internal Pemerintah (SPIP) memiliki pengaruh signifikan terhadap pencegahan fraud, pengungkapan fraud, dan pencapain Good Government Governance (GGG) di instansi pemerintah yang menjadi tanggungjawab pengawasan BPKP Sulawesi Selatan. Berdasarkan penilaian persepsional dari auditor BPKP Sulawesi Selatan yang menjadi responden penelitian ini. (2) Penilaian persepsional dari auditor BPKP Sulawesi Selatan, yang menjadi responden penelitian ini, menunjukkan pencegahan fraud di instansi pemerintah yang menggunakan Fraud Control Plan, memiliki pengaruh signifikan terhadap pencapain Good Government Governance (GGG) di instansi pemerintah yang mereka awasi. (3) tidak ditemukan pengaruh yang signifikan atas pencegahan fraud terhadap pengungkapan fraud. Begitu juga dengan pengungkapan fraud dan pencapaian Good Government Governance (GGG) di instansi pemerintah yang menjadi tanggungjawab pengawasan BPKP Sulawesi Selatan.

Lebih jauh, berdasarkan penilaian persepsional dari auditor BPKP Sulawesi Selatan yang menjadi responden penelitian ini. Hasil penelitian ini menunjukkan pentingnya melakukan penilaian efektifitas SPIP dan Fraud Control Plan secara berkala kepada para auditor Internal pemerintah,guna dapat memberikan masukan untuk lebih meningkatkan fungsi sistem-sistem tersebut dalam membantu pemerintah mencapai Good Government Governance.

Adapun keterbatasan penelitian ini terletak pada ruang lingkup penelitian ini yang hanya berfokus penilaian berbasis persepsi, yang tentu tidak dapat menjelaskan kedalaman fakta sesungguhnya terkait kondisi SPIP di instansi pemerintah.

Sehingga saran untuk penelitian selanjutnya antara lain: (1) penelitian kedepan sebaiknya dapat meneliti dengan pendekatan berbeda, misal pendekatan kualitatif untuk menilai secara mendalam kasus yang spesifik berkaitakan dengan penerapan SPIP di instansi pemerintah, (2) penelitian selanjutnya dapat menggunakan pendekatan penelitian berbasis data sekunder guna membandingkan persepsi auditor BPKP dengan indikator-indikator sekunder pencapaian Good Government Governance untuk instansi pemerintah.

\section{Ucapan Terimakasih}

Terima kasih sebesar-besarnya dihaturkan kepada KEMENRISTEK-DIKTI. Penelitian ini tidak akan terselenggara tanpa bantuan dana dari Kementrian RISTEKDIKTI dalam program Hibah Penelitian Dosen Pemula. Juga kepada LPPM UNIFA, beserta teman-teman dosen dan mahasiswa UNIFA yang turut berkontribusi positif dalam penelitian ini

\section{Daftar Pustaka}

ACFE. (2006). Fraud Examination Manual. New York: Inc, Austin.

Albrecht, W. S., Howe, K. R., \& Romey, M. B. (1984). Deterring Fraud: The Internal Auditor's Perspective (The Institute of Internal Auditors Research Foundation, Altamonte Springs, Florida, USA). Google Scholar.

Aprilia, \& Ghozali, I. (2013). Teknik Penyusunan Skala Likert. Semarang: BP UNDIP.

Arens, A. (2006). Auditing and Assurance Service An Integrated Approach. Pearson International Edition. New Jersey: Prentice Hall International.

Badara, M. S., \& Saidin, S. Z. (2013). The relationship between audit experience and internal audit effectiveness in the public sector organizations. International Journal of Academic Research in Accounting, Finance and Management Sciences, 3(3), 329-339.

Baker, D. R. (1990). Relationship of Internal Accounting Control and Occurrence of 
Computer Fraud. Nova University, Michigan.

Bertot, J. C., Jaeger, P. T., \& Grimes, J. M. (2010). Using ICTs to create a culture of transparency: E-government and social media as openness and anti-corruption tools for societies. Government Information Quarterly, 27(3), 264-271.

Bierstaker, J. L., Brody, R. G., \& Pacini, C. (2006). Accountants' perceptions regarding fraud detection and prevention methods. Managerial Auditing Journal, 21(5), 520535.

Boynton, W. C., \& Johnson, R. N. (2006). Modern auditing: Assurance services and the integrity of financial reporting. Wiley.

BPKP. (2010). Fraud Control Plan . Retrieved from http://www.bpkp.go.id/konten/418/FCP.bpkp.

BPKP. (2017). Sejarah BPKP . Retrieved from http://www.bpkp.go.id/konten/4/Sejarah-

Singkat-BPKP.bpkp.

Cangemi, M. P., \& Singleton, T. (1996). Managing the audit function: A corporate audit department procedures guide (Vol. 3). Wiley.

Carlo Bertot, J., Jaeger, P. T., Grimes, J. M., Bertot, J. C., Jaeger, P. T., \& Grimes, J. M. (2012). Promoting transparency and accountability through ICTs, social media, and collaborative e-government. Transforming Government: People, Process and Policy, 6(1), 78-91. https://doi.org/10.1108/17506161211214831

Cavalluzzo, K. S., \& Ittner, C. D. (2004). Implementing performance measurement innovations: evidence from government. Accounting, Organizations and Society, 29(3), 243-267.

Cendrowski, H., \& Martin, J. P. (2007). Handbook of fraud deterrence. Hoboken, New Jersey: Jhon Wiley \& Sons, Inc.

Croom, S., \& Brandon-Jones, A. (2007). Impact of e-procurement: experiences from implementation in the UK public sector. Journal of Purchasing and Supply Management, 13(4), 294-303.

Eriyanto. (2010). 65 Tahun Kemerdekaan RI dan Pemenuhan Agenda Reformasi. Jurnal Sekretariat Negara RI-NEGARAWAN, Agustus(17), 10-25.
Ghozali, I., \& Latan, H. (2015). Partial Least Squares, Konsep, Teknik Dan Aplikasi Menggunakan Program Smartpls 3.0 Untuk Penelitian Empiris. Semarang: Badan Penerbit UNDIP.

Graycar, A., \& Sidebottom, A. (2012). Corruption and control: a corruption reduction approach. Journal of Financial Crime, 19(4), 384-399. https://doi.org/10.1108/13590791211266377

Jones, P. C., \& Bates, G. (1990). Public Sector Auditing: Practical Tech an Integrated Approach. London. UK: Chapman and Hall.

Kottler, P., \& Keller, K. L. (2008). Manajemen Pemasaran (edisi 12) PT. Indeka, Jakarta.

KPK. (2017a). Statistik Tindak Pidana Korupsi.

Retrieved from https://acch.kpk.go.id/id/statistik/tindakpidana-korupsi

KPK. (2017b). TPK Berdasarkan Jenis Perkara. Retrieved from https://acch.kpk.go.id/id/statistik/tindakpidana-korupsi/tpk-berdasarkan-jenisperkara

Kuhn Jr, J. R., Ahuja, M., \& Mueller, J. (2013). An examination of the relationship of IT control weakness to company financial performance and health. International Journal of Accounting \& Information Management, 21(3), 227-240.

Law, P. (2011). Corporate governance and no fraud occurrence in organizations: Hong Kong evidence. Managerial Auditing Journal, 26(6), 501-518.

Manning, G. A. (2005). Financial investigation and Forensic Accounting. London: Taylor and Francis.

Moeller, R. R. (2009). Brink's modern internal auditing: A common body of knowledge. John Wiley \& Sons.

Pedneault, S., Silverstone, H., Rudewicz, F., \& Sheetz, M. (2012). Forensic accounting and fraud investigation for non-experts. John Wiley \& Sons.

Pickett, K. H. S. (2010). The internal auditing handbook. John Wiley \& Sons.

Rae, K., \& Subramaniam, N. (2008). Quality of internal control procedures: Antecedents and moderating effect on organisational justice and employee fraud. Managerial Auditing Journal, 23(2), 104-124.

Rezaee, Z., \& Riley, R. (2010). Financial 
Statement Fraud-Prevention and Detection. New Jersey: John Wiley and Sons, Inc.

Robbins, S. P., \& Judge, T. A. (2006). Perilaku organisasi. Edisi Bahasa Indonesia. Jakarta. PT. Indeks Kelompok Gramedia.

Sarens, G., \& De Beelde, I. (2006). Internal auditors' perception about their role in risk management: A comparison between US and Belgian companies. Managerial Auditing Journal, 21(1), 63-80.

SUARA.COM. (2015). Johan Budi: Korupsi Semakin Canggih dan Sulit Terlacak. Retrieved from http://www.suara.com/wawancara/2015/07/20/070000/johan-budikorupsi-semakin-canggih-sulit-terlacak

Transparency International. (2016). Corruption Perception Index. Retrieved from https://www.transparency.org/news/feature/c orruption_perceptions_index_2016

Tuanakotta, T. M. (2010). Akuntansi Forensik \& Audit Investigatif-2/E.
UNDP. (2011). A users' Guide to Measuring Local Governance . Retrieved from http://www.undp.org/content/undp/en/home/ library.html

Vinten, G., Alleyne, P., \& Howard, M. (2005). An exploratory study of auditors' responsibility for fraud detection in Barbados. Managerial Auditing Journal, 20(3), 284-303.

Vona, L. W. (2012). Fraud risk assessment: building a fraud audit program. John Wiley \& Sons.

William Jr, M., Glover, S., \& Prawitt, D. (2016). Auditing and assurance services: A systematic approach. McGraw-Hill Education.

Zahra, S. A., Priem, R. L., \& Rasheed, A. A. (2005). The antecedents and consequences of top management fraud. Journal of Management, 31(6), 803-828. 